\title{
Helicobacter pylori in First Nations and recent immigrant populations in Canada
}

\author{
Nicola L Jones MD FRCPC PhD ${ }^{1,2}$, Naoki Chiba MD MSc FRCPC 3,4 , Carlo Fallone MD FRCPC ${ }^{5}$, \\ Alan Thomson MD FRCPC ${ }^{6}$, Richard Hunt MB FRCPC ${ }^{7}$, Kevan Jacobson MD FRCPC ${ }^{8}$, Karen Goodman PhD $^{9}$; \\ on behalf of Canadian Helicobacter Study Group participants
}

\begin{abstract}
NL Jones, N Chiba, C Fallone, et al; on behalf of Canadian Helicobacter study group participants. Helicobacter pylori in First Nations and recent immigrant populations in Canada. Can J Gastroenterol 2012;26(2):97-103.
\end{abstract}

The diminishing prevalence of Helicobacter pylori infection among most segments of the Canadian population has led to changes in the etiologies and patterns of associated upper gastrointestinal diseases, including fewer peptic ulcers and their complications. Canadian Aboriginals and recent immigrants are among populations in which the prevalence of $\mathrm{H}$ pylori infection remains high and, therefore, the health risks imposed by $\mathrm{H}$ pylori remain a significant concern. Population-based strategies for $\mathrm{H}$ pylori eradication in groups with a low prevalence of infection are unlikely to be cost effective, but such measures are attractive in groups in which the prevalence rates of infection remain substantial. In addition to a lower prevalence of peptic ulcers and dyspepsia, the public health value of eradication may be particularly important if this leads to a reduction in the prevalence of gastric cancer in high prevalence groups. Therefore The Canadian Helicobacter Study Group held a conference that brought together experts in the field to address these issues, the results of which are reviewed in the present article. Canadians with the highest prevalence of $\mathrm{H}$ pylori infection are an appropriate focus for considering the health advantages of eradicating persistent infection. In Canadian communities with a high prevalence of both $\mathrm{H}$ pylori and gastric cancer, there remains an opportunity to test the hypothesis that $H$ pylori infection is a treatable risk factor for malignancy.

Key Words: Gastric cancer; Helicobacter pylori; Immigrants; Native Canadians

Canadian Aboriginals and recent immigrants are among populations in which the prevalence of Helicobacter pylori infection remains high; hence, the health risks imposed by $H$ pylori remain a significant concern. Therefore, The Canadian Helicobacter Study Group held a conference in October 2010, which brought together experts in the fields of adult and pediatric gastroenterology, microbiology, pathology, epidemiology, Aboriginal health and community health. The focus of the conference was to review the health risks of $H$ pylori infection in at-risk populations as well as the potential health benefits of adopting an eradication strategy in these at-risk populations. Relevant data focusing on these topics was presented, and followed by discussion in which the existing data were reviewed and critiqued. The meeting was recorded, and the content, discussion and conclusions generated from the meeting were then summarized by the authors of the manuscript followed by input from all of the participants (Appendix).

\section{L'Helicobacter pylori au sein des populations des Premières nations et des populations de nouveaux immigrants au Canada}

La prévalence décroissante de l'infection à Helicobacter pylori dans la plupart des segments de la population canadienne a suscité des modifications aux étiologies et aux profils des maladies œsogastroduodénales connexes, y compris un moins grand nombre d'ulcères gastroduodénaux et de leurs complications. Les peuples autochtones et les nouveaux immigrants font partie des populations au sein desquelles la prévalence d'infection à $H$ pylori demeure élevée et, par conséquent, les risques imposés par le $H$ pylori sur la santé demeurent une grave préoccupation. Les stratégies en population pour éradiquer le $\mathrm{H}$ pylori au sein des groupes ayant une faible prévalence d'infection sont peu susceptibles d'être rentables, mais sont intéressantes dans les groupes où le taux de prévalence d'infection demeure élevé. Outre une plus faible prévalence d'ulcères gastroduodénaux et de dyspepsie, la valeur de l'éradication sur la santé publique peut être particulièrement importante si elle permet de faire fléchir la prévalence de cancer gastrique dans les groupes à forte prévalence. C'est pourquoi le groupe d'étude canadien de l'Helicobacter a tenu une conférence qui a rassemblé des experts dans le domaine pour aborder ces questions, dont les résultats sont analysés dans le présent article. Les Canadiens ayant la plus forte prévalence d'infection à $H$ pylori constituent un point de mire pertinent pour évaluer les avantages de l'éradication d'une infection persistante pour la santé. Dans les collectivités canadiennes où on remarque une forte prévalence à la fois de $H$ pylori et de cancer gastrique, on peut vérifier l'hypothèse selon laquelle l'infection à $H$ pylori représenterait un facteur de risque traitable de malignité.

H pylori is a Gram-negative bacterium that typically colonizes the mucin layer of the gastric mucosal epithelium (1). At one time, it is likely that $\mathrm{H}$ pylori infected the majority of the human population (2). Infection is strongly correlated with human crowding and poor sanitation (3). The prevalence of infection has diminished markedly over the past several decades in Canada, as in most other industrialized countries, but can be found in up to $80 \%$ of the population in some developing nations (4). The overall prevalence of $\mathrm{H}$ pylori infection in Canada appears to be in the range of $20 \%$ to $30 \%$ $(5,6)$; however, reports from specific subsets of the population indicate substantial variability. In children, who typically have a lower risk of $\mathrm{H}$ pylori infection than adults, the prevalence rate was only $7.1 \%$ in patients referred to a tertiary care centre for upper gastrointestinal symptoms (7). The median age in these patients was 11.7 years, with a range of five to 17.6 years. Conversely, the prevalence in a First Nations community in northern Manitoba was $56 \%$, even though ages

${ }^{1}$ Division of Gastroenterology, Hepatology and Nutrition, The Hospital for Sick Children; ${ }^{2}$ Departments of Paediatrics and Physiology, University of

Toronto, Toronto; ${ }^{3}$ Division of Gastroenterology, McMaster University, Hamilton; ${ }^{4}$ Guelph General Hospital, Guelph, Ontario; ${ }^{5}$ Division of

Gastroenterology, McGill University Health Centre, McGill University, Montreal, Quebec; ${ }^{6}$ Division of General Internal Medicine, University of

Alberta, Edmonton, Alberta; 7 Division of Gastroenterology and Farncombe Family Digestive Health Research Center, McMaster University, Hamilton,

Ontario; ${ }^{8}$ Division of Gastroenterology, British Columbia's Children's Hospital and CFRI, University of British Columbia, Vancouver, British

Columbia; ${ }^{9}$ Department of Medicine, University of Alberta, Edmonton, Alberta

Correspondence: Dr Nicola L Jones, Department of Pediatrics, The Hospital for Sick Children, 555 University Avenue, Toronto, Ontario M5G 1X8.

Telephone 416-813-7734, fax 416-813-6531, e-mail nicola.jones@sickkids.ca

Receieved for publication May 12, 2011. Accepted June 25, 2011. 
ranged from six weeks to only 12 years, and the screening was conducted in all volunteers and not necessarily in those with symptoms (8). In adults, a study conducted in Toronto, Ontario, found a prevalence of $23.1 \%$ (5), whereas rates as high as $95 \%$ have been reported in some Aboriginal communities (9). The largest emigrations to Canada in the most recent Statistics Canada census were from China, India, the Philippines and Pakistan (10), all of which have high endemic rates of $\mathrm{H}$ pylori infection that would be expected to be represented in these immigrants (11).

The pathogenic role of $H$ pylori infection in diseases of the gastrointestinal tract is well established but imperfectly understood. Although $\mathrm{H}$ pylori infection has been identified as a major etiological factor for peptic ulcers, chronic active gastritis, gastric atrophy, gastric carcinoma and gastric mucosa-associated lymphoid tissue (MALT) lymphoma (12-15), the lifetime risk of a related-disease in infected patients is less than $20 \%$. For peptic ulcer disease, the most common pathology associated with $H$ pylori, the lifetime risk is approximately $10 \%$ (16). Higher risks of disease have been reported in Asia (17), suggesting the importance of additional cofactors for this pathology such as genetic susceptibility, environmental exposures or bacterial virulence factors. Eradication of $\mathrm{H}$ pylori can prevent and cure peptic ulcer disease (18). MALT lymphomas may also be treated by H pylori eradication. In a multicentre study (15), complete regression, suggesting a potential for cure, was achieved in $62 \%$ of patients after successful $H$ pylori eradication. However, the lifetime risk of MALT lymphoma in patients infected with $H$ pylori is less than $1 \%$ (1), rendering a pre-emptive population-based eradication of $\mathrm{H}$ pylori impractical with prevention of MALT lymphoma as an isolated goal.

The lifetime risk of gastric cancer is approximately $1 \%$ in patients infected with $H$ pylori (1). Gastric cancer is the second most common cause of cancer death worldwide (19), although only the ninth most common cause of cancer death in Canada (20). Importantly, the outcome of gastric cancer is poor, with overall five-year survival rates of 28\% (21). Despite evidence that $H$ pylori is an important cause of gastric cancer, a well-controlled and prospective study to demonstrate that eradication is a viable public health strategy to prevent gastric cancer has yet to be conducted.

$H$ pylori infection of the gastric mucosa produces chronic active gastritis, which is the initial step in the pathophysiology of all, or most, $\mathrm{H}$ pylori-related diseases. While the majority of infected individuals tolerate gastritis without any apparent adverse health consequences, the patterns of gastritis are important. Specifically, the RR for peptic ulcer disease is greatest in those with antral predominant gastritis sparing the body and fundus, which increases gastrin release and hyperacidity, while an increased RR of gastric cancer is most closely associated with gastritis in the corpus of the stomach, where it results in atrophic changes associated with hypo- or achlorhydria and dysregulation of cell growth (22).

Eradication of H pylori infection prevents and cures recurrent peptic ulcer disease (23), and there is a strong basis on which to predict that eradication will also provide protection from gastric cancer. In 1994, the WHO concluded that there was sufficient epidemiological and histological evidence to characterize H pylori as a carcinogen (24). This designation followed a series of studies that provided compelling evidence of a causal association, including a United States (US) cohort study involving almost 130,000 individuals in whom the odds of gastric carcinoma among $\mathrm{H}$ pylori-infected individuals were increased 3.6-fold overall, and 18-fold specifically in women, over individuals without $H$ pylori infection (25). In Japan, a cohort study (26) found that the odds were increased sixfold, and there was a highly statistical increased risk $(\mathrm{P}=0.0009)$ with increased levels of $\mathrm{H}$ pylori antibody. A case-control study from the United Kingdom associated H pylori infection with a 2.77-fold increased risk of gastric cancer (27). In addition, $2.9 \%$ of patients with $H$ pylori infection compared with none of those without $H$ pylori developed gastric cancer among 1526 Japanese patients with a gastrointestinal complaint who were followed for seven years (28).
The inflammatory response within the gastric mucosa that is observed in individuals infected with $H$ pylori infection likely contributes to the risk of neoplasia. Inflammation from stimuli such as infection or irritation is a well demonstrated cause of cancer in other anatomical sites including the colon, cervix and lungs (29). In the gastric mucosa, as in other sites, the dysregulation of cell cycles and increased cell turnover that is driven by cytokines and growth factors is believed to increase the risk of neoplastic mutations (30). In a study of gastric biopsies taken from 70 patients of which approximately one-half were infected with $H$ pylori (31), stratification according to those with normal epithelia, gastritis, gastritis with intestinal metaplasia or gastric carcinoma revealed increased epithelial cell turnover in the presence of gastritis even in the absence of metaplasia. Moreover, eradication of $H$ pylori was associated with a reduction in gastritis and cell proliferation, which in turn would be expected to reduce the risk of dysplasia and its potential to promote mutation.

The RRs for gastric carcinoma may be mediated by a wide variety of factors characteristic of the specific strain or of the host. Virulence factors, such as CagA or Vac status, which appear to be useful for identifying $H$ pylori-infected patients with a high risk of progressing to neoplastic lesions (32), may not have any direct carcinogenic effects, but increase risk of dysplastic mutations and cancer by increasing the degree of inflammation (33). Specific histological or clinical characteristics associated with increased gastric cancer risk, such as atrophy, intestinal metaplasia and achlorhydria, may also be linked to these or other virulence factors (34). However, the host response both with regard to inflammation and to the downstream molecular events that may mediate specific steps toward malignant transformation may be heterogeneous. For example, one of many proposed pathways of malignancy is upregulation of interleukin-6, which is linked to activation of the transcription factor STAT3. STAT3, a promoter of epithelial cell hyperproliferation in animal models, has been found to be upregulated in biopsies taken from human gastric cancers (35). In this and other examples, multiple feedback mechanisms, as well as redundant and interrelated molecular signaling that affect cytokine expression and protein phosphorylation, may explain unequal RRs for a trajectory from inflammation to malignancy (36).

The mechanisms by which $H$ pylori promotes gastric cancer, particularly the relative role of virulence factors and their relationship to intestinal metaplasia, are important for understanding the potential benefit of eradication for preventing or halting the neoplastic process. However, the timing of eradication is likely to be critical because the pathophysiology may no longer be dependent on the presence of $H$ pylori infection once the process has been initiated. In a prospective study that randomly assigned patients with or without precancerous lesions to $H$ pylori eradication, no cancers developed during a 7.5 year follow-up period after eradication in those without precancerous lesions, whereas eradication had no protective effect in patients with precancerous lesions when compared with placebo (28). The potential importance of eradicating $H$ pylori before the development of intestinal metaplasia is an important consideration when attempting to calculate the health benefit from a population-based eradication program. Due to the prolonged latency period between infection and cancer, clinical studies capable of demonstrating benefit will require follow-up for a decade or longer in a patient population with both a high prevalence of $H$ pylori infection and a high incidence of gastric cancer. Despite the falling rates of $H$ pylori infection in Canada, studies of the feasibility of a population-based eradication program in highrisk populations have been recommended previously (37). Aboriginals, particularly those in Arctic communities, and selected immigrant groups appear to be attractive targets of such initiatives.

\section{POPULATIONS AT RISK IN CANADA}

\section{Native Canadians}

The most significant effort to evaluate the health risks posed by $\mathrm{H}$ pylori infection in Canadian populations with a high prevalence of infection was initiated in 2006 by the Canadian North Helicobacter pylori 
Working Group (CANHelp), which was specifically created to evaluate the impact of $H$ pylori infection among individuals living in Canada's Arctic communities $(38,39)$. The initial impetus for this endeavour was the concern among health providers regarding the high rate of gastric cancer in Aklavik, Northwest Territories, relative to non-Aboriginals in Canada (39). In an initial survey conducted in 2008 involving the urea breath test (UBT), the rate of $H$ pylori infection in this community was 55\% (38), reinforcing concern among the community members that $H$ pylori might be related to the observed increase in gastric cancer risk. However, prevalence alone may not account for the risk of gastric cancer. In a study of an Aboriginal community in northwestern Manitoba, the high seropositive rate of $\mathrm{H}$ pylori infection (95\%), of which most were positive for the CagA virulence factor, was consistent with a high rate of hospitalizations for peptic ulcer disease (9). Two studies that evaluated the prevalence of $\mathrm{H}$ pylori among Aboriginals living in Arctic communities of Canada $(8,40)$ documented a high prevalence of infection in children as well as in adults. In one, $67 \%$ of children were infected by two years of age. While gastric cancer rates have not always differed in Aboriginals when compared with non-Aboriginal groups, confounding variables, such as differences in lifespan, may obscure a relative difference.

Similar concern about an increased prevalence of $\mathrm{H}$ pylori infection and gastric cancer has been raised in other Aboriginal communities as well as in Arctic communities outside of Canada. In studies from Greenland, Alaska and Russia, the prevalence of infection ranged from $47 \%$ to $88 \%(41-43)$. In a comparison of $H$ pylori-related diseases among Aboriginal populations in the US, those from the Arctic communities had the highest rates of hospitalization from peptic ulcer disease, gastric carcinoma and MALT lymphoma (44). Similar data are needed for Aboriginal communities in Canada.

Based on these observations, several initiatives, in addition to CANHelp, have been created to investigate the relationship between $H$ pylori infection and risk of upper gastrointestinal diseases, including gastric cancer. In particular, the Circumpolar Helicobacter Pylori Working Group (CHPWG), which includes Canadian participation, has provided a platform on which to share information. In Alaska, surveillance data collected by the US Centers for Disease Control show that the increased prevalence of $H$ pylori infection is unique to individuals living in Aboriginal communities and is not shared by Alaskans who do not reside in these communities (45). The high rate of $\mathrm{H}$ pylori infection was initially identified in a study investigating the high prevalence of anemia in Aboriginals (46). A variety of etiological factors were evaluated including iron intake, stool parasites and upper gastrointestinal bleeding, but the anemia was ultimately linked to gastrointestinal bleeding from $H$ pylori-induced gastritis $(46,47)$. In the US, cancer rates have been traditionally higher in American Indians versus whites $(48,49)$. In a study that compared Indian populations from different regions, the incidence rates of cancer were often more than twice as high for Indians versus non-Hispanic whites (NHWs) (49). The exception was on the east coast, where Aboriginal and NHW cancer incidence rates were similar. The differences were greatest among Alaskan Indians versus NHWs. In patients older than 65 years of age, the rate was more than four times higher among Alaskan Aboriginals than NHWs (134.5 versus 31.1 per 100,000 [RR 4.33]), and approximately twice as high as the next highest Aboriginal rate, which was 69.6 per 100,000 among Indians from the Northern Plains.

The increased prevalence of $\mathrm{H}$ pylori infection among Aboriginals is attributed to the same set of factors that account for the high prevalence of $H$ pylori infection in developing nations (50). These include many of the consequences of limited income, including crowded living conditions, bed-sharing in childhood, lack of refrigeration, and lack of running water and other obstacles to regular personal hygiene. Such conditions are common in many Arctic communities. Independent of the costs or other obstacles to improving living conditions among Aboriginals, resistance to change in traditional lifestyles is a potential obstacle to control of $\mathrm{H}$ pylori transmission.

\section{IMMIGRANT POPULATIONS IN CANADA}

Immigrants to Canada from countries with high endemic rates of $\mathrm{H}$ pylori infection, such as China or India, also continue to demonstrate high rates of infection relative to the first-generation of the same ethnic groups born in Canada (5). Because spontaneous eradication of $\mathrm{H}$ pylori is uncommon (51), foreign-born Canadians who arrive with this infection can be expected to harbour this bacterium indefinitely. In a study of the prevalence and risk factors for $\mathrm{H}$ pylori infection in Ontario, the RR for infection was 2.9 times greater among those born in a country other than Canada and who immigrated after 20 years of age (5). A similar RR was found for immigrants to the US (52). In a US study comparing generational differences in the prevalence of infection among immigrant families from Latin America (53), the age-adjusted OR for $\mathrm{H}$ pylori infection was 9.70 for foreign-born adults relative to the second-generation, although differences fell after additional adjustments for educational level and crowding.

$H$ pylori-infection prevalence in recent immigrants may rival those observed in some northern Aboriginal communities, but populationbased strategies for eradicating infection and preventing new infection in immigrants may pose a different set of problems than those faced in Aboriginal groups. Foreign-born immigrants do not necessarily live in well-defined communities and, therefore, may be more difficult to identify for screening and treatment unless screening and treatment is performed at the time of immigration. Moreover, given the older average age of immigrants versus Aboriginals, the anticipated reduction in the rate of infection transmitted to others is lower, so that the benefit from a test-and-treat strategy may be less. In contrast, greater access to health care services may lower the cost of a test-and-treat strategy in an urban immigrant population relative to Aboriginals. The result is that different calculations may be needed to predict the benefit-to-risk ratio from a test-and-treat strategy among these two groups, even when prevalence rates are similar, particularly when calculated in the context of cost.

\section{CHALLENGES TO ELIMINATING H PYLORI INFECTION IN HIGH-RISK POPULATIONS}

Of the health benefits anticipated from $H$ pylori eradication, prevention of gastric cancer is the most significant perhaps in relation to years of life saved. According to data from the US (54), only $23 \%$ of gastric cancers are localized at the time of diagnosis. Similar to many other malignancies, the frequency with which gastric cancer is discovered at an advanced stage, when the opportunity for curative treatment is diminished, makes prevention an attractive strategy. While populations with both a high prevalence of $H$ pylori infection and a high rate of gastric cancer constitute a particularly attractive target for public health initiatives to prevent gastric cancer with $\mathrm{H}$ pylori eradication, other significant health benefits may also be achieved. In particular, prevention of complicated peptic ulcer disease can be expected to reduce the risk from life-threatening upper gastrointestinal bleeding.

There are several limitations to consider before initiating a population-based eradication initiative in any population. In addition to potential practical barriers, such as gaining consent and support among a target group, the understanding of biological events that link infection with the risk of malignancy remains limited. In a prospective Japanese study that followed 1526 patients with upper gastrointestinal complaints, including peptic ulcer disease and dyspepsia (14), gastric cancers occurred exclusively in those with $H$ pylori infection, reaching an incidence of $4.7 \%$ in patients with nonulcer dyspepsia over a mean follow-up period of 7.8 years. However, this study only compared uninfected individuals rather than those who achieved successful eradication before infection. There is no evidence that eradication can eliminate an established malignancy. In a placebo-controlled study that evaluated the risk of cancer development after eradication, protection was only observed in patients without precancerous lesions, defined as gastric atrophy, intestinal metaplasia or gastric dysplasia, at the time of study entry (28). Based on a study from Japan (55), recurrent gastric cancer can be reduced by two-thirds with the eradication of $H$ pylori infection. Although another study by the same group found 
that $H$ pylori eradication did not prevent cancer in individuals who had already developed atrophic gastritis (56), a population-based strategy of test-and-treat was predicted to reduce gastric cancer rates by more than $80 \%$, yielding large economic benefits.

In Canada, approximately one million individuals identify themselves as Aboriginal, of which approximately $5 \%$ are Inuit (57). Given the epidemiology of $\mathrm{H}$ pylori in the human host, an increased prevalence of infection is likely to be limited to Aboriginal communities that harbour risk factors for $\mathrm{H}$ pylori infection, including poor socioeconomic circumstances, crowded living conditions and limited access to running water. The CANHelp initiatives, now supported by data demonstrating a high prevalence of $\mathrm{H}$ pylori infection in isolated Arctic communities, where these conditions are most common, include efforts to reduce health risks by providing information on the sources and strategies to diminish risk exposure. Such initiatives require sensitivity to Aboriginal culture as well as collaboration with community leaders seeking to ensure a community benefit. If adequate data can be collected to anticipate a significant improvement in health from a populationbased $H$ pylori eradication program, buy-in from community leaders and the rest of the community will be essential for successful implementation.

If the benefits of a population-based program for eradication of $\mathrm{H}$ pylori infection are projected to justify the cost, other potential challenges require consideration. The rates of resistance to the antibiotics typically used in the multidrug combinations for eradication appear to be high in Aboriginal communities (K Goodman, Aklavik $\mathrm{H}$ pylori Project personal communication). To reduce the impact of resistance to commonly used three-drug regimens, several strategies, such as four-drug regimens (58), longer courses of three- or four-drug regimens (59), or the addition of newer, more expensive antibiotics (60), can be effective; however, each of these strategies must be weighed carefully in the context of goals and costs. Moreover, strategies will need to be implemented to enhance adherence. The large volume of literature comparing first-, second- and third-line regimens in areas with high rates of resistance may or may not be useful for guiding treatment choice in a population-based program that may require relatively simple regimens to achieve adequate adherence.

In particular, the traditional first-line eradication regimens endorsed by the Canadian Helicobacter Study Group were twice-daily triple therapies consisting of a proton pump inhibitor and two antibiotics administered for seven days (61). Longer durations of treatment, such as 10 days, or four-drug versus three-drug therapies, can offer modest but potentially clinically significant improvements in eradication rates, particularly among those with resistance to one of the antibiotics in the combination (62,63). Resistance to antibiotics make alternative, often more expensive agents, such as levofloxacin, attractive for boosting eradication rates (64), particularly in patients who have failed a previous regimen (65); however, the ideal characteristics of a regimen for a population-based eradication strategy may be different from those for an individual. Issues such as convenience, cost and adverse events may play a critical role in achieving a level of compliance important to eradication independent of the efficacy of the regimen. For individuals or population-based strategies, second- and, potentially third-line, options must be developed based on the causes of failure, particularly antibiotic resistance (66). This is an area in which evidence regarding the populations of concern discussed in the present article is lacking and, thus, open to investigation.

The foremost goal of any program developed to screen and treat $H$ pylori infection is a direct benefit for the participants. While comprehensive eradication programs may provide an important opportunity to demonstrate that gastric cancer is a preventable disease, outcomes must be predefined and measured rigorously. While it may not be feasible to document $H$ pylori eradication in all participants in a community-based screen-and-treat program, it will be prudent to prospectively define adherence, treatment failure, and treatment success for both first- and second-line regimens to document the impact of intervention with regard to benefit, risk and cost. Unlike test-andtreat strategies that reserve therapy for symptomatic patients, a benefit will be measured primarily by a reduced population-based rate of the complications of $\mathrm{H}$ pylori infection.

Protecting immigrant populations with a high prevalence of $\mathrm{H}$ pylori infection and high prevalence of gastric cancer is a potentially important public health initiative. The high prevalence of gastric cancer in several Asian countries, including China and Japan (67), has been reflected in the immigrant populations from those countries in Canada (68). Despite the absence of level-1 evidence that eradication of $\mathrm{H}$ pylori will reduce cancer risk, the circumstantial evidence is strong $(69,70)$. Targeted programs for recent immigrants or for specific immigrant communities are feasible, and should be pursued on the basis of evidence supporting a health benefit.

In the effort to target either Aboriginal or immigrant populations to reduce the risk of gastric cancer, collaboration with these communities will be essential. The history of difficult relations between Aboriginal and non-Aboriginal populations, in particular, may increase the need for evidence of a benefit from an intervention recommended from outside the community.

\section{ECONOMIC BENEFITS: ANTICIPATING OUTCOMES}

The 2008 Asia-Pacific Consensus Guidelines on Gastric Cancer Prevention (71) recommended a strategy of screening and eradicating $H$ pylori in high-risk populations, based on the anticipated probability of cancer prevention. The emphasis on high risk is based on the fact that $H$ pylori infection is a necessary but not sufficient factor for the development of gastric cancer. In cost analyses of test-and-treat eradication schemes, important variables include the cost and sensitivity of the diagnostic test, the cost and efficacy of the treatment, and the anticipated reduction in cancer risk. Based on assumptions used in one of the earliest models (72), the projected cost per year of life saved in the US was US $\$ 25,000$. A commonly accepted benchmark for an acceptable per year of life cost is dialysis, which is typically calculated to cost between US $\$ 50,000$ and US $\$ 100,000$ per year of life saved (73). When the assumptions of test sensitivity and treatment efficacy were made less favourable, the costs exceeded those that are usually acceptable for the general population, but remained attractive for Japanese Americans, the highest risk group.

In a recent study conducted in Korea (74), where the prevalence of $H$ pylori infection and gastric cancer were relatively high, the model for a test-and-treat strategy projected a modest reduction in cost (\$US800) relative to no eradication. The savings derived from an anticipated reduction in gastric cancer were accompanied by a small mortality reduction. In a simulation model conducted among ethnic Chinese males living in Singapore, the projected incremental cost effectiveness of test-and-treat was US\$16,166 per life year saved when serology was used as the screening tool, but rose to $\$ 38,792$ per life year saved with the more sensitive and specific UBT (75). Moreover, unlike the UBT, the relative cost efficacy of serology was found to remain substantial even with large changes in the underlying assumptions, such as lowering the rate of expected infection. In a model constructed with data from China, screening and treatment for $\mathrm{H}$ pylori infection at 20 years of age reduced the mean lifetime cancer risk by $14.5 \%$ in men and $26.6 \%$ in women at an anticipated cost of less than \$US1,500 per year of life saved (76).

From a public health perspective, these models anticipate a reasonable return from a test-and-treat strategy in high-risk patients. However, the underlying premise that gastric cancer will be prevented with $H$ pylori eradication remains circumstantial. Although epidemiological data support the notion that individuals without $H$ pylori infection have a very low risk of gastric cancer relative to those infected, the process of carcinogenesis is not likely to be reversible once infection has been present for an, as yet, undetermined period of time. Based on the current understanding of the relationship between gastritis, proinflammatory cytokines, hyperproliferation of epithelial cells and malignant transformation, the potential for eradication to reverse the risk of cancer remains a reasonable expectation. However, the timing is likely to be important and it may be essential to eradicate 
$H$ pylori before premalignant dysplastic lesions develop in areas of atrophic gastritis.

In regions with a high incidence of $\mathrm{H}$ pylori infection and gastric cancer, as suggested by the limited data from Arctic Aboriginal communities in Canada (38, K Goodman, Aklavik H pylori Project personal communication), the opportunity to prevent gastric cancer with a test-and-treat approach to $H$ pylori infection is considerable but, in reality, is unlikely to be proven in the short term in a prospective randomized controlled trial. Even if test-and-treat strategies lower gastric cancer risk, the anticipated risks and benefits will vary substantially with the relative efficacy of the eradication regimen.

\section{SUMMARY}

The high prevalence of $H$ pylori infection and gastric cancer in Canadian Aboriginal communities presents an important opportunity to pursue a clinical research initiative for gastric cancer prevention. Moreover, programs that merge basic and clinical research with the goal of creating realistic and effective public health programs to control $\mathrm{H}$ pylori infection in Aboriginals have the potential to yield information on the relationship between this pathogen and gastric cancer in other populations. Funding for new research and existing programs such as CANHelp should be considered an urgent priority because of the potential for a large overall public health benefit in these high-risk groups. The considerable data already generated by studies conducted in Canada and elsewhere support the current need for a focused effort to determine whether $H$ pylori eradication reduces the risk of gastric cancer. As reviewed in the present document, Aboriginal populations may provide the best target for clinical research that will answer this question. Such studies, which have a strong potential to yield health benefits to the study participants, may increase our understanding of the role of $H$ pylori and other environmental and genetic factors in the multifactorial pathogenesis of gastric cancer.

The Arctic Aboriginal communities within Canada offer an exceptional target for public health initiatives regarding $H$ pylori infection. Adverse health consequences, including a high prevalence of gastric cancer associated with $\mathrm{H}$ pylori infection, are already known. The substantial potential public health benefit is supported by the suitability of the isolated and insular Aboriginal communities for tracking the impact of a test-and-treat intervention. Within Canadian health care, investment in this research could be costeffective if confined to the target populations. This investment has the additional potential to yield information relevant for managing gastric cancer risk in non-Aboriginal groups.

There are important hurdles. The Aboriginal communities must agree that cooperation in this research is likely to produce a direct benefit. Additional studies are needed to document $H$ pylori infection prevalence and gastric cancer risk in those communities that are potential partners in this research. Detailed projections of sensitivity and cost will be needed to select the most appropriate screening test. Appropriate eradication regimens must be selected on the basis of efficacy and adherence, with particular attention devoted to antibiotic resistance rates in the Arctic Aboriginal populations. The transparency of research methods is essential for informed consent, and well-defined outcome measures are essential to document community benefit.

The Canadian Helicobacter Study Group advocates research that will determine whether a population-based test-and-treat strategy for $\mathrm{H}$ pylori is a feasible clinical initiative in the Arctic and immigrant populations. The large potential public health benefit to Canadians, including Aboriginal groups, and the state of current knowledge encourages this direction of research. Funding of this research with public monies has a strong probability of improving the health of Canadians.
ACKNOWLEDGMENTS: The authors thank Michael Bruce MD, MPH, Epidemiology Team Leader Arctic Investigations Program, US Centers for Disease Control and Prevention (USA) who presented a comprehensive information-sharing talk and contributed to fruitful discussion at the conference. They also thank medical writer Ted Bosworth for keeping a record of the meeting and constructing the initial draft of the manuscript, and The Canadian Helicobacter Study Group for providing financial support for the conference.

\begin{tabular}{|c|}
\hline 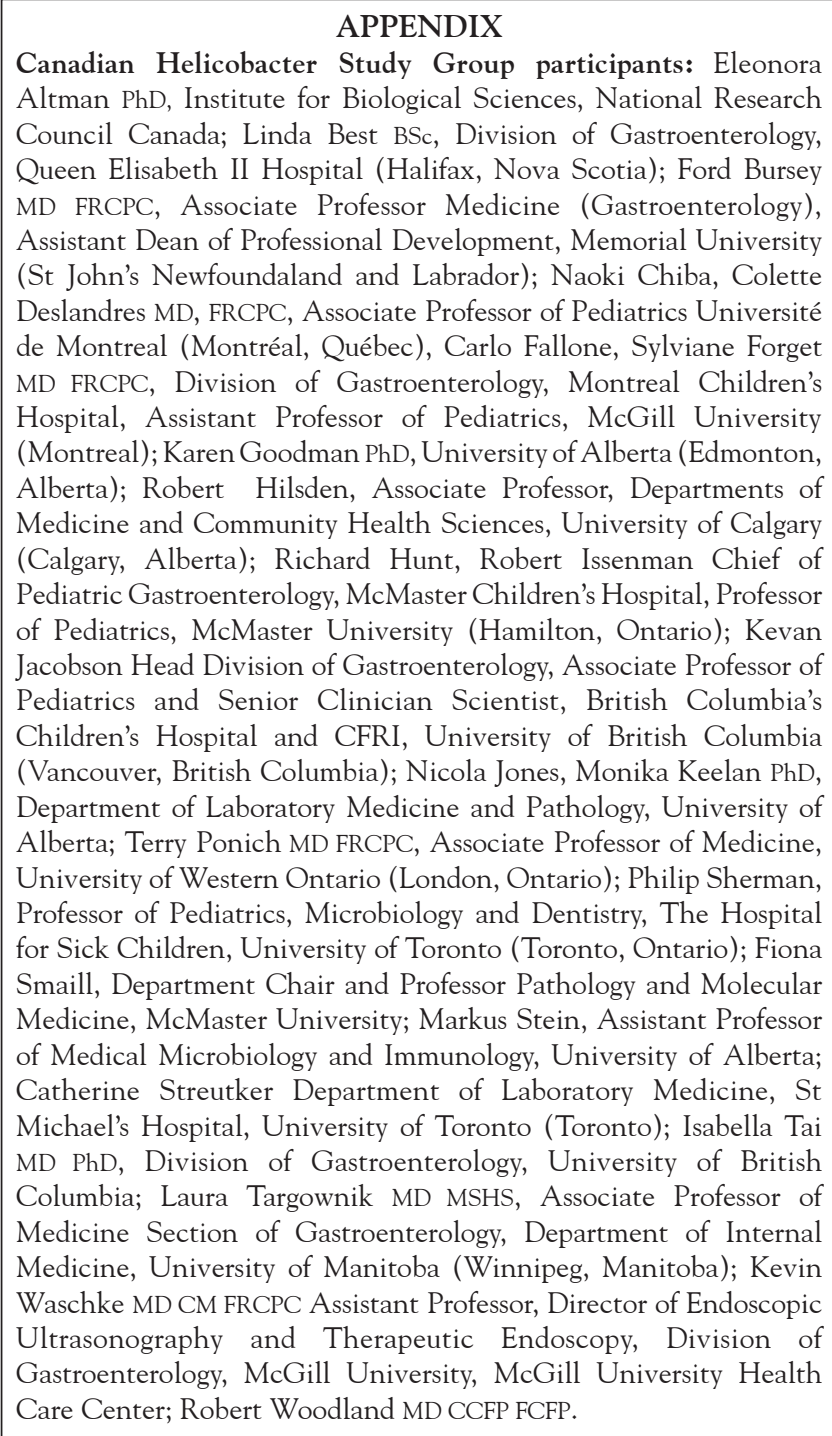 \\
\hline
\end{tabular}

\section{REFERENCES}

1. McColl KE. Clinical practice. Helicobacter pylori infection. N Engl J Med 2010;362:1597-604.

2. Everhart JE. Recent developments in the epidemiology of Helicobacter pylori. Gastroenterol Clin North Am 2000;29:559-78.

3. Graham DY, Malaty HM, Evans DG, Evans DJ Jr, Klein PD, Adam E. Epidemiology of Helicobacter pylori in an asymptomatic population in the United States. Effect of age, race, and socioeconomic status. Gastroenterology 1991;100:1495-501.

4. Graham DY, Adam E, Reddy GT, et al. Seroepidemiology of Helicobacter pylori infection in India. Comparison of developing and developed countries. Dig Dis Sci 1991;36:1084-8.

5. Naja F, Kreiger N, Sullivan T. Helicobacter pylori infection in Ontario: Prevalence and risk factors. Can J Gastroenterol 2007;21:501-6. 
6. Thomson AB, Barkun AN, Armstrong D, et al. The prevalence of clinically significant endoscopic findings in primary care patients with uninvestigated dyspepsia: The Canadian Adult Dyspepsia Empiric Treatment - Prompt Endoscopy (CADET-PE) study. Aliment Pharmacol Ther 2003;17:1481-91.

7. Segal I, Otley A, Issenman R, et al. Low prevalence of Helicobacter pylori infection in Canadian children: A cross-sectional analysis. Can J Gastroenterol 2008;22:485-9.

8. Sinha SK, Martin B, Sargent M, McConnell JP, Bernstein CN. Age at acquisition of Helicobacter pylori in a pediatric Canadian First Nations population. Helicobacter 2002;7:76-85.

9. Bernstein CN, McKeown I, Embil JM, et al. Seroprevalence of Helicobacter pylori, incidence of gastric cancer, and peptic ulcerassociated hospitalizations in a Canadian Indian population. Dig Dis Sci 1999;44:668-74.

10. Top 10 countries of birth of recent immigrants. 2006 . <www12. statcan.ca/census-recensement/2006/as-sa/97-557/table/t1-eng.cfm> (Accessed on January 22, 2011).

11. Zullo A, Cristofari F, Bragazzi MC, Hassan C. Helicobacter pylori in immigrants: a "foreign" bacterium? Intern Emerg Med 2011;6:7-8.

12. Hentschel E, Brandstatter G, Dragosics B, et al. Effect of ranitidine and amoxicillin plus metronidazole on the eradication of Helicobacter pylori and the recurrence of duodenal ulcer. N Engl J Med 1993;328:308-12.

13. Axon AT, O'Morain CA, Bardhan KD, et al. Randomised double blind controlled study of recurrence of gastric ulcer after treatment for eradication of Helicobacter pylori infection. BMJ 1997;314:565-8.

14. Uemura N, Okamoto S, Yamamoto S, et al. Helicobacter pylori infection and the development of gastric cancer. N Engl J Med 2001;345:784-9.

15. Fischbach W, Goebeler-Kolve ME, Dragosics B, Greiner A, Stolte M. Long term outcome of patients with gastric marginal zone B cell lymphoma of mucosa associated lymphoid tissue (MALT) following exclusive Helicobacter pylori eradication therapy: Experience from a large prospective series. Gut 2004;53:34-7.

16. Kuipers EJ, Thijs JC, Festen HP. The prevalence of Helicobacter pylori in peptic ulcer disease. Aliment Pharmacol Ther 1995;9(Suppl 2):59-69.

17. Schlemper RJ, van der Werf SD, Biemond I, Lamers CB. Seroepidemiology of gastritis in Japanese and Dutch male employees with and without ulcer disease. Eur J Gastroenterol Hepatol 1996;8:33-9.

18. Veldhuyzen van Zanten SJ, Sherman PM. Helicobacter pylori infection as a cause of gastritis, duodenal ulcer, gastric cancer and nonulcer dyspepsia: A systematic overview. CMAJ 1994;150:177-85.

19. Cancer Key Facts. 2010. <www.who.int/mediacentre/factsheets/ fs297/en/> (Accessed on December 12, 2010).

20. Canadian Cancer Statistics 2001. <www.cancer.ca/Canada-wide/ Aboutcancer/Cancerstatistics/PowerPointslides.aspx?sc_lang=en $>$ (Accessed on October 31, 2011).

21. American Cancer Society. Stomach cancer; 5-Year Survival Statistics by Stage. 2011. <www.cancer.org/cancer/stomachcancer/ detailedguide/stomach-cancer-survival-rates> (Accessed on February 25, 2011).

22. McColl KE, el-Omar E, Gillen D. Interactions between H pylori infection, gastric acid secretion and anti-secretory therapy. Br Med Bull 1998;54:121-38.

23. Forbes GM, Glaser ME, Cullen DJ, et al. Duodenal ulcer treated with Helicobacter pylori eradication: Seven-year follow-up. Lancet 1994;343:258-60.

24. IARC Working Group on the Evaluation of Carcinogenic Risks to Humans. Schistosomes, liver flukes and Helicobacter pylori. Lyon, June 7 to 14, 1994. IARC Monogr Eval Carcinog Risks Hum 1994;61:1-241.

25. Parsonnet J, Friedman GD, Vandersteen DP, et al. Helicobacter pylori infection and the risk of gastric carcinoma. N Engl J Med 1991;325:1127-31.

26. Watabe H, Mitsushima T, Yamaji Y, Okamoto M, et al. Predicting the development of gastric cancer from combining Helicobacter pylori antibodies and serum pepsinogen status: A prospective endoscopic cohort study. Gut 2005;54:764-8.

27. Forman D, Newell DG, Fullerton F, et al. Association between infection with Helicobacter pylori and risk of gastric cancer: Evidence from a prospective investigation. BMJ 1991;302:1302-5.

28. Wong BC, Lam SK, Wong WM, et al. Helicobacter pylori eradication to prevent gastric cancer in a high-risk region of China: A randomized controlled trial. JAMA 2004;291:187-94.
29. Coussens LM, Werb Z. Inflammation and cancer. Nature 2002;420:860-7.

30. Fox JG, Wang TC. Inflammation, atrophy, and gastric cancer. J Clin Invest 2007;117:60-9.

31. Szaleczky E, Pronai L, Molnar B, Berczi L, Feher J, Tulassay Z. Increased cell proliferation in chronic Helicobacter pylori positive gastritis and gastric carcinoma - correlation between immunohistochemistry and Tv image cytometry. Anal Cell Pathol 2000;20:131-9.

32. Gonzalez CA, Figueiredo C, Lic CB, et al. Helicobacter pylori cagA and vacA genotypes as predictors of progression of gastric preneoplastic lesions: A long-term follow-up in a high-risk area in Spain. Am J Gastroenterol 2011;106:867-74.

33. Tao R, Hu MF, Lou JT, Lei YL. Effects of H pylori infection on gapjunctional intercellular communication and proliferation of gastric epithelial cells in vitro. World J Gastroenterol 2007;13:5497-500.

34. Polk DB, Peek RM Jr. Helicobacter pylori: Gastric cancer and beyond. Nat Rev Cancer 2010;10:403-14.

35. Jackson CB, Judd LM, Menheniott TR, et al. Augmented gp130. mediated cytokine signalling accompanies human gastric cancer progression. J Pathol 2007;213:140-51.

36. Egloff AM, Grandis JR. Response to combined molecular targeting: Defining the role of P-STAT3. Clin Cancer Res 2011;17:393-5.

37. Sullivan T, Ashbury FD, Fallone CA, et al. Helicobacter pylori and the prevention of gastric cancer. Can J Gastroenterol 2004;18:295-302.

38. Goodman KJ, Jacobson K, Veldhuyzen van Zanten S. Helicobacter pylori infection in Canadian and related Arctic Aboriginal populations. Can J Gastroenterol 2008;22:289-95.

39. Cheung J, Goodman K, Munday R, et al. Helicobacter pylori infection in Canada's arctic: Searching for the solutions. Can J Gastroenterol 2008;22:912-6.

40. McKeown I, Orr P, Macdonald S, et al. Helicobacter pylori in the Canadian arctic: Seroprevalence and detection in community water samples. Am J Gastroenterol 1999;94:1823-9.

41. Johansen JK, Sehested A, Myrhoj T, Ladefoged K, Krogfelt KA. Helicobacter pylori infection in Greenlandic patients with dyspepsia. Int J Circumpolar Health 2004;63(Suppl 2):219-20.

42. Reshetnikov OV, Nikitin YP, Kholmogortsev MV, Kurilovich SA, Pycllik OA. Helicobacter pylori in a Chukotka Native male population. Int J Circumpolar Health 1998;57(Suppl 1):293-5.

43. Zhu J, Davidson M, Leinonen M, et al. Prevalence and persistence of antibodies to herpes viruses, Chlamydia pneumoniae and Helicobacter pylori in Alaskan Eskimos: The GOCADAN Study. Clin Microbiol Infect 2006;12:118-22.

44. Demma LJ, Holman RC, Sobel J, et al. Epidemiology of hospitalizations associated with ulcers, gastric cancers, and Helicobacter pylori infection among American Indian and Alaska Native persons. Am J Trop Med Hyg 2008;78:811-8.

45. Lynn TV, Bruce MG, Landen M, et al. Helicobacter pylori infection among non-Native educators in Alaska. Int J Circumpolar Health 2007;66:135-43

46. Yip R, Limburg PJ, Ahlquist DA, et al. Pervasive occult gastrointestinal bleeding in an Alaska native population with prevalent iron deficiency. Role of Helicobacter pylori gastritis. JAMA 1997;277:1135-9.

47. Parkinson AJ, Gold BD, Bulkow L, et al. High prevalence of Helicobacter pylori in the Alaska native population and association with low serum ferritin levels in young adults. Clin Diagn Lab Immunol 2000; 7:885-8.

48. Wiggins CL, Becker TM, Key CR, Samet JM. Stomach cancer among New Mexico's American Indians, Hispanic whites, and non-Hispanic whites. Cancer Res 1989;49:1595-9.

49. Wiggins CL, Perdue DG, Henderson JA, et al. Gastric cancer among American Indians and Alaska Natives in the United States, 1999-2004. Cancer 2008;113(5 Suppl):1225-33.

50. Hotez PJ. Neglected infections of poverty among the indigenous peoples of the arctic. PLoS Negl Trop Dis 2010;4:e606.

51. Xia HH, Talley NJ. Natural acquisition and spontaneous elimination of Helicobacter pylori infection: Clinical implications. Am J Gastroenterol 1997;92:1780-7.

52. Everhart JE, Kruszon-Moran D, Perez-Perez GI, Tralka TS, McQuillan G. Seroprevalence and ethnic differences in Helicobacter pylori infection among adults in the United States. J Infect Dis 2000;181:1359-63.

53. Tsai CJ, Perry S, Sanchez L, Parsonnet J. Helicobacter pylori infection in different generations of Hispanics in the San Francisco Bay Area. Am J Epidemiol 2005;162:351-7. 
54. Surveillance Epidemiology and End Results (SEER). National Cancer Institute, 2010. < http://seer.cancer.gov/statfacts/html/ stomach.html > (Accessed on January 5, 2011).

55. Fukase K, Kato M, Kikuchi S, Inoue K, et al. Effect of eradication of Helicobacter pylori on incidence of metachronous gastric carcinoma after endoscopic resection of early gastric cancer: An open-label, randomised controlled trial. Lancet 2008;372:392-7.

56. Asaka M, Kato M, Graham DY. Strategy for eliminating gastric cancer in Japan. Helicobacter 2010;15:486-90.

57. Aboriginal Peoples. Statistics Canada, 2006. <www12.statcan.ca/ census-recensement/2006/rt-td/ap-pa-eng.cfm> (Accessed on January 5, 2011).

58. Sun Q, Liang X, Zheng Q, et al. High efficacy of 14-day triple therapy-based, bismuth-containing quadruple therapy for initial Helicobacter pylori eradication. Helicobacter 2010;15:233-8.

59. Fuccio L, Minardi ME, Zagari RM, Grilli D, Magrini N, Bazzoli F. Meta-analysis: Duration of first-line proton-pump inhibitor based triple therapy for Helicobacter pylori eradication. Ann Intern Med 2007;147:553-62.

60. Liou JM, Lin JT, Chang CY, et al. Levofloxacin-based and clarithromycin-based triple therapies as first-line and second-line treatments for Helicobacter pylori infection: A randomised comparative trial with crossover design. Gut 2010;59:572-8.

61. Hunt R, Thomson AB. Canadian Helicobacter pylori consensus conference. Canadian Association of Gastroenterology. Can J Gastroenterol 1998;12:31-41.

62. Laine L, Hunt R, El-Zimaity H, Nguyen B, Osato M, Spenard J. Bismuth-based quadruple therapy using a single capsule of bismuth biskalcitrate, metronidazole, and tetracycline given with omeprazole versus omeprazole, amoxicillin, and clarithromycin for eradication of Helicobacter pylori in duodenal ulcer patients: A prospective, randomized, multicenter, North American trial. Am J Gastroenterol 2003;98:562-7.

63. Essa AS, Kramer JR, Graham DY, Treiber G. Meta-analysis: Four-drug, three-antibiotic, non-bismuth-containing "concomitant therapy" versus triple therapy for Helicobacter pylori eradication. Helicobacter 2009;14:109-18.

64. O'Connor A, Gisbert JP, McNamara D, O'Morain C. Treatment of Helicobacter pylori infection 2010. Helicobacter 2010;15(Suppl 1):46-52.
65. Saad RJ, Schoenfeld P, Kim HM, Chey WD. Levofloxacin-based triple therapy versus bismuth-based quadruple therapy for persistent Helicobacter pylori infection: A meta-analysis. Am J Gastroenterol 2006;101:488-96.

66. Gisbert JP. Second-line rescue therapy of Helicobacter pylori infection. Therap Adv Gastroenterol 2009;2:331-56.

67. Garcia M, Jemal A, Ward EM, Center MM. Global Cancer Facts \& Figures 2007. Atlanta: American Cancer Society, 2007.

68. Chung CW, Streutker C, Kim YJ, Grantcharov TP, Brezden CB. Retrospective clinico-pathologic review of gastric cancer in an inner city Canadian hospital. J Clin Oncol 2010;28(Suppl):e14649.

69. Hunt RH. Will eradication of Helicobacter pylori infection influence the risk of gastric cancer? Am J Med 2004;117(Suppl 5A):86S-91S.

70. Takayama S, Wakasugi T, Funahashi H, Takeyama H. Strategies for gastric cancer in the modern era. World J Gastrointest Oncol 2010;2:335-41.

71. Fock KM, Talley N, Moayyedi P, et al. Asia-Pacific consensus guidelines on gastric cancer prevention. J Gastroenterol Hepatol 2008;23:351-65.

72. Parsonnet J, Harris RA, Hack HM, Owens DK. Modelling costeffectiveness of Helicobacter pylori screening to prevent gastric cancer: A mandate for clinical trials. Lancet 1996;348:150-4.

73. Lee CP, Chertow GM, Zenios SA. An empiric estimate of the value of life: Updating the renal dialysis cost-effectiveness standard. Value Health 2009;12:80-7.

74. Shin DW, Yun YH, Choi IJ, Koh E, Park SM. Cost-effectiveness of eradication of Helicobacter pylori in gastric cancer survivors after endoscopic resection of early gastric cancer. Helicobacter 2009; 14:536-44.

75. Xie F, Luo N, Lee HP. Cost effectiveness analysis of populationbased serology screening and (13)C-Urea breath test for Helicobacter pylori to prevent gastric cancer: A markov model. World J Gastroenterol 2008;14:3021-7.

76. Yeh JM, Kuntz KM, Ezzati M, Goldie SJ. Exploring the costeffectiveness of Helicobacter pylori screening to prevent gastric cancer in China in anticipation of clinical trial results. Int J Cancer 2009;124:157-66. 


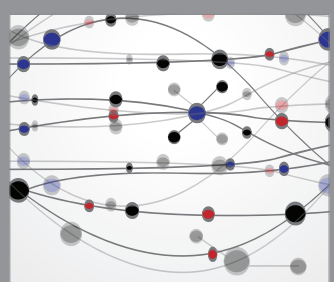

The Scientific World Journal
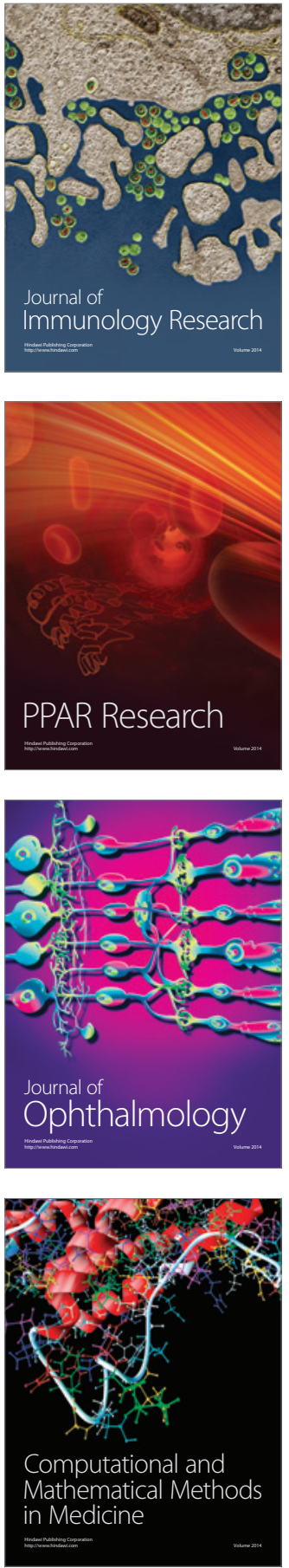

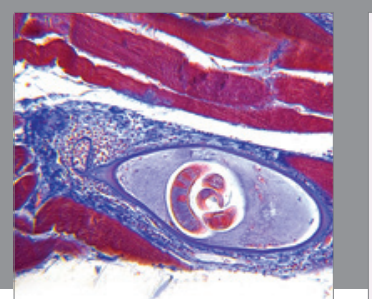

Gastroenterology Research and Practice

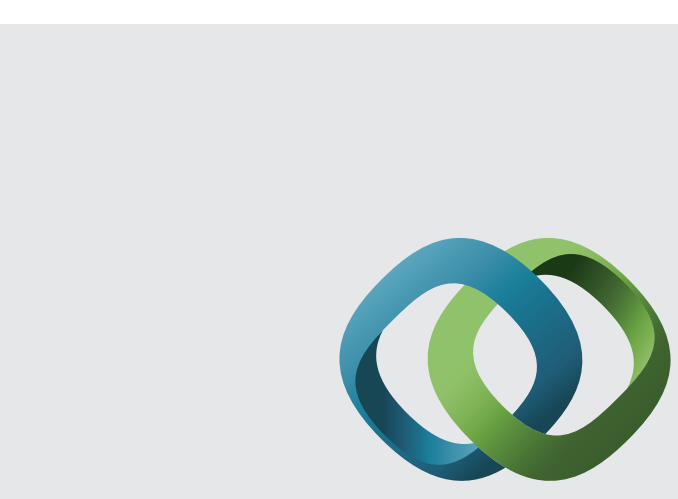

\section{Hindawi}

Submit your manuscripts at

http://www.hindawi.com
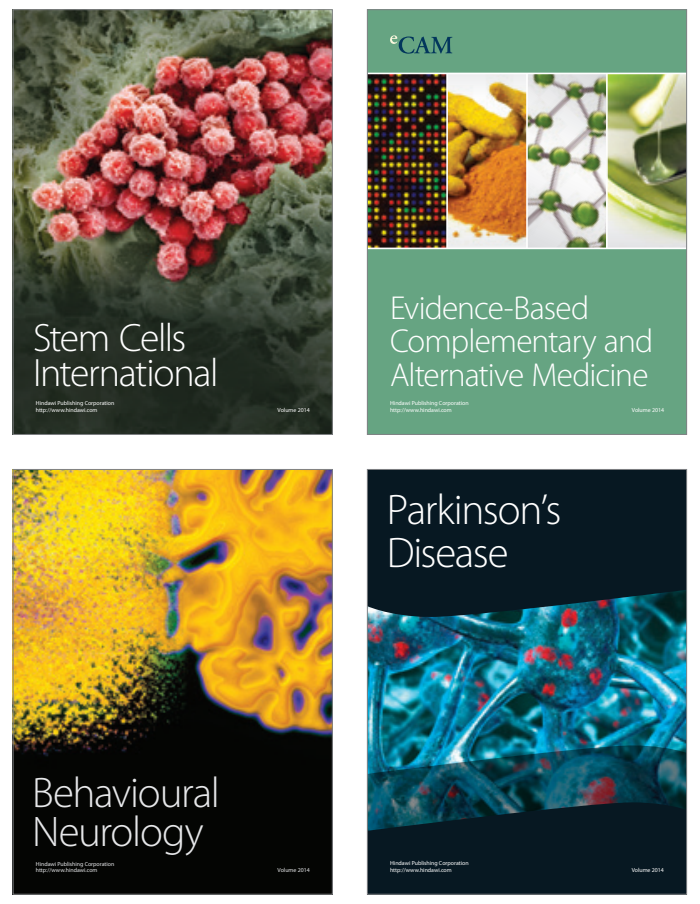
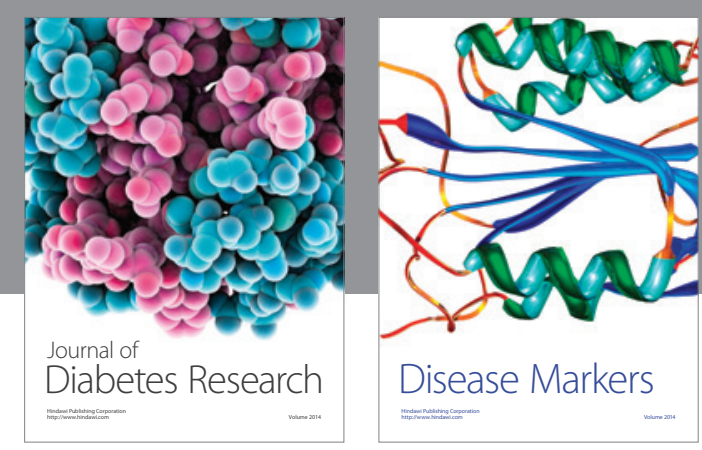

Disease Markers
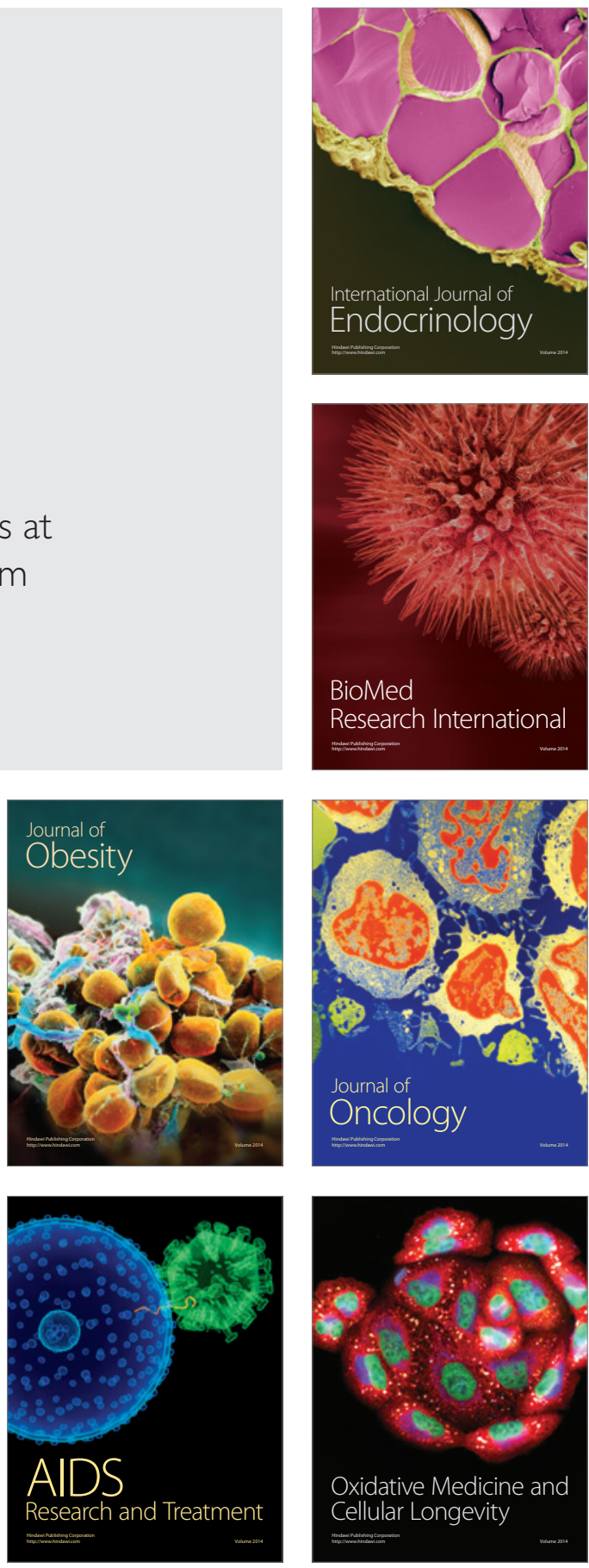